\title{
Voluminous laryngeal schwannoma excision with a mini-invasive external approach: a case report
}

\author{
Exeresi mediante approccio mini-invasivo di un voluminoso schwannoma laringeo: \\ un case report
}

M. TULLI, S. BONDI, M. BUSSI

Department of Otolaryngology Head and Neck Surgery, San Raffaele Scientific Institute, Milan, Italy

\begin{abstract}
SUMMARY
Laryngeal schwannomas are extremely uncommon. We present a case of bulky supraglottic schwannoma with involvement of the preepiglottic and superior paraglottic spaces. Clinical findings, computed tomography and magnetic resonance images are presented. These characteristics are typical, however not specific to schwannomas. For definitive diagnosis, histology and immunohistochemistry are necessary. We present an external mini-invasive approach that allowed us to both obtain diagnosis and provide definitive treatment for this kind of voluminous laryngeal tumour.
\end{abstract}

KEY WORDS: Schwannoma $\bullet$ Neurilemmoma $\bullet$ Nerve sheath tumours $\bullet$ Supraglottic larynx $\bullet$ Mini-invasive approach

\section{RIASSUNTO}

Gli schwannomi laringei sono una variante estremante rara dei tumori benigni della laringe. Riportiano il caso di un voluminoso schwannoma localizzato nella regione sopraglottica, con coinvolgimento dello spazio pre-epiglottico e paraglottico superiore. I segni e i sintomi di presentazione di tale tumore e le principali caratteristiche radiologiche riscontrabili alla TC e alla RMN sono descritte dettagliatamente. Pur non permettendo una diagnosi certa, tali caratteristiche, tipiche ma non esclusive dello schwannoma, sono importanti per sospettare il tumore in fase preoperatoria. La diagnosi definitiva necessita comunque dell'esame istologico e immunoistochimico, ottenibile mediante biopsia escissionale. Nello specifico descriviamo l'utilizzato nuovo approccio open mini-nvasivo che consente di ottenere la exeresi completa del tumore, con un ottimo outcome funzionale.

PAROLE CHIAVE: Schwannoma $\bullet$ Neurilemmoma $\bullet$ Tumori della guaina dei nervi $\bullet$ Laringe sopraglottica $\bullet$ Approccio miniinvasivo

Acta Otorhinolaryngol Ital 2017;37:242-244

\section{Introduction}

Schwannomas are the most common benign peripheral nerve sheath tumours and originate from Schwann cells of the peripheral nervous system. Laryngeal schwannomas are rare and usually present as insidious, slow-growing, submucosal masses, bringing diagnostic and management challenges for the otolaryngologist. Appropriate therapy requires complete excision with minimal injury to uninvolved areas of the larynx. Both endoscopic and open approaches have been described depending on tumour features ${ }^{12}$.

We describe a case of bulky laryngeal schwannoma of the preepiglottic space and discuss our management. We present a new possible approach to benign and encapsulated tumours that allowed both mini-invasive radical resection of the tumour and complete recovery with short hospitalisation time.

\section{Case report}

A 61-year-old man presented to the otolaryngology clinic with an 18-month history of foreign-body sensation and hoarseness. He denied dyspnoea, dysphagia, otalgia or recent respiratory tract infection. He had quit smoking about 40 years prior to presentation. Family history was negative for remarkable disease, with no case of laryngeal tumours or hereditary diseases.

Flexible fiberoptic laryngoscopy revealed the presence of a bulky submucosal mass in the right aryepiglottic fold with suspected involvement of the pre-epiglottic space. It occupied the ipsilateral piriform sinus and appeared cystic in nature (Fig. 1A). The laryngeal airway was decreased, but sufficient and both vocal folds were mobile. No cervical lymph nodes were palpable. Computed tomography (CT) performed in another hospital identified a paramedian supraglottic mass. It was characterised by a cystic appearance and clear margins with no evidence of cartilage erosion. Magnetic resonance imaging (MRI) identified a round mass that occupied the preepiglottic and superior paraglottic spaces. The mass pushed the epiglottis and right aryepiglottic fold posteriorly and the false vocal cord posteromedially. It had hyperintense signal on T2 

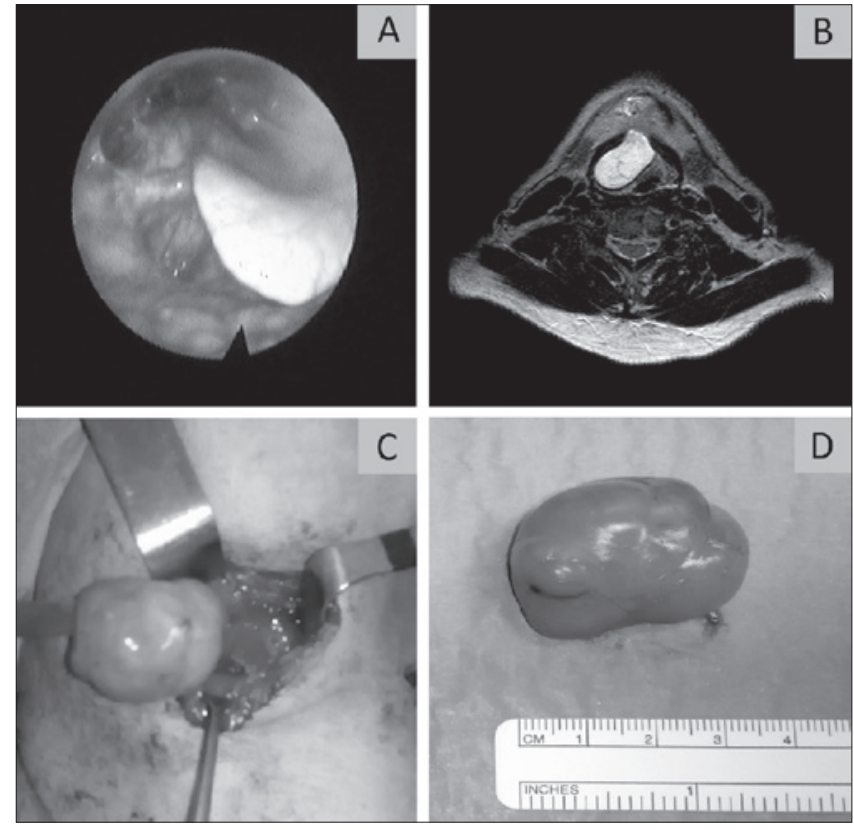

Fig. 1. (A) Endoscopic view of the lesion; (B) T2-weigthed MRI image of the mass; (C) surgical procedure for removal of the tumour; (D) surgical specimen.

weighted imaging and hypointense signal on $\mathrm{T} 1$ with wall enhancement after gadolinium (Fig. 1B). The radiological findings were suspicious for benign encapsulated lesions such as minor salivary gland adenoma or schwannoma.

Due to the dimension of the mass, the patient underwent surgery with an external approach. A horizontal median skin incision of $3.5 \mathrm{~cm}$ was made above the upper edge of the thyroid cartilage in a skin crease. Subplatysmal flaps were raised and the midline raphe was identified. Proceeding in depth at the midline, the thyroid cartilage and thyrohyoid membrane were exposed. To obtain good exposure of the area, the ipsilateral thyrohyoid muscle was sectioned and the remaining muscles were divaricated. The thyrohyoid membrane was cut with access to the preepiglottic space. Eventually the mass was removed by blunt dissection, taking care to maintain the integrity of the capsule and overlying laryngeal mucosa and preserving the trunk of the internal branch of the superior laryngeal nerve (Fig. 1C). Having achieved satisfactory haemostasis, a drain was placed to prevent supraglottic haematoma. At the end of the procedure, no tracheostomy was necessary and the respiratory space was checked by fibroscopy $20 \mathrm{~min}$ later in the recovery room.

The surgical specimen was a solid, oval shape and capsulated mass and measured $3 \times 2.5 \times 2 \mathrm{~cm}$ (Fig. 1D). On microscopic evaluation, the tumour fulfilled Enzinger and Weiss's diagnostic criteria for schwannoma: (1) presence of a capsule, (2) presence of Antoni A and/or Antoni B areas, and (3) positivity of S-100 reaction ${ }^{23}$. Furthermore, Verocay bodies were visible and no interspersed axons were present.
In the postoperative period, the patient did not present any vocal fold motility impairment, laryngeal mucosa sensitivity deficit, dyspnea, or dysphagia. The patient was discharged two days after surgery. A 7 months, follow-up examination showed disappearance of the foreign body sensation and an excellent vocal outcome.

\section{Discussion}

Schwannomas (also called neurilemmomas) are encapsulated tumours made entirely of benign neoplastic Schwann cells. The vast majority of schwannomas occur sporadically as single lesions, affecting patients of all ages, reaching a peak between 20 and 50 years, without associated lifestyle risk factors ${ }^{4}$. About $25 \%$ to $45 \%$ of all schwannomas occur in the head and neck region, the majority in the parapharyngeal space.

Laryngeal schwannomas are uncommon lesions and represent 0.1 to $1.5 \%$ of all benign laryngeal tumours ${ }^{256}$. The majority of schwannomas in the larynx originate either from the aryepiglottic fold or the false cords and then grow in the supraglottic compartment. The internal branch of the superior laryngeal nerve seems to be the most frequent nerve of origin. Macroscopically, laryngeal schwannomas appear as submucosal, smooth, well-encapsulated, firm masses and grow eccentrically to the nerve of origin ${ }^{7}$. Histologically the Schwannoma must meet the diagnostic criteria of Enzinger and Weiss mentioned above, as fulfilled by our patient.

The clinical symptoms strictly depend on the location, size and direction of the laryngeal schwannoma growth. Most patients are asymptomatic until the tumour reaches a large size and leads to conflict with surrounding structures. The typical symptomatology is constituted by long-standing history of hoarseness and foreign body sensation in the throat, dysphagia, or inspiratory dyspnea with stridor. On laryngoscopy, a laryngeal schwannoma appears like a submucosal mass. Paralysis or hypomobility of the ipsilateral vocal cord can be present ${ }^{23}$. The very slow growth (in the order of years), the absence of pathological lymphadenopathy and the lack of weight loss are characteristics indicating the benignity of this neurogenic tumour. Good family history and complete clinical examination of the patient is required to detect hereditary disease (neurofibromatosis or schwannomatosis).

With regards to diagnostic imaging methods, $\mathrm{CT}$ and MRI are most frequently indicated. CT and MRI imaging of schwannomas show the typical features of a benign lesion and can provide a preoperative estimation of the extent and nerve of origin ${ }^{5}$. The clinical and radiological characteristics are typical, but not specific to schwannomas. Definitive diagnosis is provided by histology and immunohistochemistry.

Previous reports indicate that fine needle aspiration cytology (FNAC) is often inconclusive ${ }^{18}$. Incisional biopsy has 
higher diagnostic efficacy, but (1) exposes the patient to an increased risk of relapse; (2) requires an additional surgery for exeresis of the tumour (increasing the risks and the costs) and (3) leads to formation of a scar on the site of mucosal incision, making subsequent excision more difficult and necessarily wider with a higher risk of early and late complications ${ }^{110}$.

We believe that when there is an indication to remove a submucosal capsulated laryngeal lesion, that does not present signs of malignancy, the best choice is excisional biopsy. In fact, this procedure allows us to simultaneously obtain a diagnosis and initiate definitive treatment of laryngeal schwannoma or other benign lesions.

The literature shows that the main differential diagnoses for laryngeal schwannomas include benign laryngeal tumours (neurofibroma, lipoma, adenoma, chondroma, papilloma, paraganglioma,) and non-neoplastic lesions (internal laryngocele, ectopic thyroglossal duct cyst, laryngeal cyst). Malignant lesions should, however, also be excluded.

Traditionally the surgical excision of the mass is the treatment of choice ${ }^{8}$. Adjuvant treatment (either radiotherapy or chemotherapy) is not contemplated. Appropriate surgical therapy requires complete excision of the mass with minimal injury to uninvolved areas of the larynx, laryngeal mucosa and healthy structures. The surgical approach may be selected by the size and site of the tumour, and tracheotomy is not always required.

If the tumour is small and superficial or localised in the glottis or peduncolated with good endolaryngeal exposure, the best choice is an endoscopic approach ${ }^{259}$. The advantages of this approach include a less-invasive procedure, absence of scar in the neck and fewer days of hospitalisation (1-5 days). For voluminous tumours, an external approach may offer the best exposure for complete extra-capsular excision in a single block and allow preservation of the laryngeal mucosa while minimising complications and maximising postoperative voice outcome ${ }^{1}$. The most frequently used open approaches are the median thyrotomy ${ }^{26}$ and lateral thyrotomy ${ }^{13}$. Recently, Ueha et al. proposed a suprathyroid alar cartilage approach (STACA) for submucosal laryngeal tumours that includes sacrifice of the ipsilateral prelaryngeal muscles, a larger lateral incision of thyrohyoid membrane and tracheostomy ${ }^{9}$. In contrast, our mini-invasive approach gives excellent oncological and functional results and at the same time minimises risk, hospital stay and costs. Indeed, only one thyrohyoid muscle was sectioned and repaired and tracheostomy was not necessary. The patient was discharged after 36 hours and voice outcome was good.

We believe that by relying on the characteristics of the tumour and the patient, the treatment must be tailored and, respecting oncological radicality, should be the least invasive as possible. We believe that for bulky submucosal supraglottic tumuors this should be the initial approach. If this approach proves inadequate, it is simple to switch to a more invasive approach (e.g. removing a portion of thyroid lamina). After treatment, long-term follow-up for possible recurrence is appropriate, although to date it is unclear what the appropriate duration should be.

\section{References}

1 Cohen S, Sinacori JT, Courey MS. Laryngeal schwannoma: diagnosis and management. Otolaryngol-Head Neck Surg 2004;130:363-5.

2 Rosen FS, Pou AM, Quinn FB. Obstructive supraglottic schwannoma: a case report and review of the literature. Laryngoscope 2002;112:997-1002.

3 Meric F, Arslan A, Cureoglu S, et al. Schwannoma of the larynx: case report. Eur Arch Otorhinolaryngol 2000;257:555-7.

4 Pilavaki M, Chourmouzi D, Kiziridou A, et al. Imaging of peripheral nerve sheath tumors with pathologic correlation. Pictorial review. Eur J Radiol 2004;52:229-39.

$5 \mathrm{Xu}$ J, Zheng Y, Li G, et al. A rare finding of multiple schwannomas in the epiglottis. Otolaryngol Head Neck Surg 2012;147:1160-1.

6 Cadoni G, Bucci G, Corina L, et al. Schwannoma of the larynx presenting with difficult swallowing. Otolaryngol Head Neck Surg 2000;122:773-4.

7 Skovronsky DM, Oberholtzer JC. Pathologic classification of peripheral nerve tumors. Neurosurg Clin N Am 2004;15:157-66.

8 Zhang H, Changping C, Wang S, et al. Extracranial head and neck schwannomas: a clinical analysis of 33 patients. Laryngoscope 2007;117:278-81.

9 Ueha R, Nito T, Sakamoto T, et al. Supra-thyroid alar cartilage approach for complete resection of laryngeal submucosal tumors and postoperative voice quality. Eur Arch Otorhinolaryngol 2015;271:2907-13.

10 Palva T, Jokinen K, Karja J. Neurilemmoma (schwannoma) of the larynx. J Laryngol Otol 1975;89:203-7. 